Enisa Uspenski

Univerzitet umetosti u Beogradu Fakultet dramskih umetnosti Katedra za teoriju i istoriju enisa.uspenski@gmail.com
УДК 821.161.1.09"18/20"

https://doi.org/10.18485/slavistika.2021.25.1.13

Оригинални научни рад примљено 11.05.2021.

прихваћено за штампу 17.06.2021.

\title{
FANTASTIKA REALNOG U DOKUMENTARISTIČKOJ PROZI SVETLANE ALEKSIJEVIČ U POREĐENJU S UMETNIČKIM POSTUPKOM FJODORA DOSTOJEVSKOG
}

U radu se ispituju moguće dodirne tačke dokumentarističke proze Svetlane Aleksijevič s književnim postupkom Fjodora Dostojevskog. Osnovna hipoteza rada zasniva se na tvrdnji Svetlane Aleksijevič da je za njeno stvaralaštvo Dostojevski imao prvorazredni značaj, kao i na konstataciji da su za Svetlanu Aleksijevič, jednako kao i za Dostojevskog, važne činjenice života. Svetlana Aleksijevič u postupku neposrednog posmatranja i posredne interpretacije činjenica života usvaja etički princip ,neokretanja glave od stvarnosti“, koji je u svojim delima proklamovao i promovisao Dostojevski. Pogled posmatrača fokusiran na predmet pruža iskustvo prelaska duha u materiju. Ovakav odnos prema stvarnosti daje realizmu Dostojevskog i nefikcionalnoj prozi Svetlane Aleksijevič intonaciju fantastičnog, što i jeste predmet našeg rada, koji smo teorijski potkrepili stavovima o fantastičnoj prozi Cvetana Todorova.

Ključne reči: Aleksijevič, Dostojevski, činjenica života, pogled, fantastika.

Starting from Svetlana Alexievich's thesis that Fyodor Dostoevski had a great influence on her work, the paper examines the possible similarities of her documentary prose with Dostoevsky's literary process. The main hypothesis is based on the idea that for Alexievich, as well as for Dostoevsky, the facts of life are as important as the view of the observer who realizes the experience of the transition of spirit into substance. This attitude towards reality gives Dostoevsky's realism and Alexievich's non-fictional literature a dose of fantasy, which is the subject of our work, which we have theoretically supported with Tzvetan Todorov's teachings on fantastic prose.

Key words: Alexievich, Dostoevsky, fact of life, view, fiction.

Već sam naslov ovog rada zvuči kao oksimoron i ne samo zbog toga što se njime povezuju suprotni pojmovi „fantastično“ i „realno“, već i zato što je ovde reč upravo o dokumentarističkoj prozi Svetlane Aleksijevič. Kao što je poznato, dodela Nobelove nagrade ovoj književnici izazvala je burne reakcije koje su podelile kritičku javnost i izvan granica ruskog jezičkog područja. Kao osnovni razlog osporavanja navodi se estetika žanra dela Svetlane Aleksijevič, kojom se dovodi u pitanje sama književnost kao takva. Da to nije književnost i da je Nobelova nagrada više politička nego književna stvar - tvrdili su mnogi i politički i literarni neistomišljenici Svetlane Aleksijevič.

Što se tiče žanra u kojem ova autorka piše - reč je o prozi, odnosno ,romanu glasova“, zasnovanom na autentičnim iskazima sagovornika, učesnika i očevidaca krupnih istorijskih događaja. Dakle ,poetika“ dela Svetlane Aleksijevič temelji se na istinitosti događaja i činjenica koji su u funkciji dekonstrukcije velikih istorijskih i socioloških narativa. Ako uzmemo u obzir provereni teorijski stav da ,sva književnost - izuzev poezije - izmiče kategorijama istinitog i lažnog“" onda nam se 
stavovi kritičara Svetlane Aleksijevič mogu učiniti umesnim. Ipak, sama autorka insistira na tome da je njeno delo književno i da je plod umetničke transformacije, koja se u ovom slučaju sastoji u ,prevođenju“ usmenog, „običnog“ govora na „konvencionalni jezik književnosti“”, odnosno umetničku jezičku strukturu. To nas opet vraća u začarani krug, jer se radi o jeziku u kojem je dokazivanje istine nemoguće, s obzirom da je „istina odnos između reči i stvari koje te reči određuju, a u književnosti, međutim, te stvari ne postoje" (Todorov 2010 79-80). Ipak, Cvetan Todorov koji je sedamdesetih godina zastupao ova načela, u tekstu „Pojam književnosti“ govori da je danas u savremenoj nauci o književnosti „nemoguće podvući granicu između onoga što jeste i što nije književnost" (Todorov 1975: 355), te da su struktura i funkcionalnost književnog dela međusobno uslovljene. No, ako se ovim putem može dokazati da dokumentaristička proza Svetlane Aleksijevič jeste književnost, ostaje pitanje kako ta književnost, koja se proglašava izričito ne-fikcionalnom (non-fiction), može imati veze s pojmom „fantastično“, kada znamo da je „fantastično uvek vezano za fikciju i doslovnost“" (Todorov 2010: 73). U daljem izlaganju pokušaćemo da objasnimo tezu, iznetu u naslovu rada, koju ćemo ovde kratko definistati tvrdnjom da „fantastično“ kod Svetlane Aleksijevič nastaje iz viška, odnosno produžetka doslovnosti zasnovane na višku, iskustvom proverenih, činjenica. U tom smislu ćemo Svetlanu Aleksijevič dovesti u vezu s Dostojevskim i pojmom fantastični realizam, odnosno realizam $u$ višem smislu. ${ }^{1}$ Ovakvo povezivanje nam na prvi pogled može izgledati čudno i iznenađujuće, kao što je iznenađujući iskaz Svetlane Aleksijevič da bez Dostojevskog verovatno ne bi bilo ni njenih romana, o čemu svedoči u jednom od svojih intervjua: „Jednom u prošlosti bila sam poražena rečima Dostojevskog, koje me i dalje vode kroz život, o tome kako se trudio da shvati 'koliko ima čoveka u čoveku'. Upravo u tome, u skupljanju čoveka - i ja vidim smisao rada jednog pisca“" (Алексиевич 2016).

Kao što je poznato, savremena kritika je isključivala Dostojevskog iz sfere realizma, a on je, s druge strane, odgovarajući na primedbe oponenata, definisao svoj stvaralački metod na sledeći način:

Ja imam potpuno drugačije shvatanje o stvarnosti i realizmu, od naših realista i kritičara. Moj idealizam je realniji od njhovog. Gospode! Ispričati sve, šta smo mi, Rusi, za poslednjih 10 godina preživeli u našem duhovnom razvoju - pa zar neće realisti povikati, to je fantazija! A međutim to je iskonski, pravi realizam! To upravo i jeste realizam, samo dublji, dok oni plivaju u plićaku. $<\ldots>$ Dubok im je taj realizam - nema šta! Njihovim realizmom ne može se objasniti ni stoti deo od realnih činjenica koje su se desile u

${ }^{1} \mathrm{O}$ pojmu fantastični realizam, odnosno realizam $u$ višem smislu, postoji opširna literatura, među kojom treba istaći sledeće studije: Joves, Malkom V. Dostoevsky after Bakhtin: Reading in Dostoevsky's fantastic realism. Camridge University Press. Cambridge; Nev York Port Chester. Melbourne; Sydney, 1990; Захаров В. Н. «Концепция фантастического в эстетике Ф. М. Достоевского», Художественный образ и историческое сознание. Петрозаводск, 1974, 98125; Захаров Н. В. Фантастическое в эстетике и творчестве Ф. М, Достоевского: Автореф. дис...канд.филол.наук.Петрозаводск, 1975). Mi se u datom radu ne bavimo predstavljanjem, kritikom ili polemikom s definicijama pojma u navedenim studijama, već, nadovezujući se na njegovo akademski prihvaćeno značenje (Русские писатели 1800-1917, библиографический словарь), dajemo svoj pristup i primere. 
stvarnosti. A mi smo našim idealizmom predviđali čak i činjenice (kurziv -

E. U.) Dešavalo se! (Достоевский 1974: 239).

Iz ovoga vidimo da je i za Dostojevskog, kao i za Svetlanu Aleksijevič realna činjenica, - dakle nešto što se desilo u stvarnosti — osnovna jedinica u stvaranju književnog teksta. Poznato je da je Dostojevski bio strastveni ,kolekcionar“ primera ljudskih patnji i stradanja, koje je pronalazio u novinskim člancima, sudskim hronikama ili ispovestima sagovornika iz različitih društvenih slojeva. Svetlana Aleksijevič je u potrazi za stvarnim stanjem stvari obilazila gradove i sela, od vrata do vrata, razgovarajući s ljudima koji su učestvovali u Drugom svetskom ratu, Černobiljskoj katastrofi, Avganistanskom ratu - kako bi dobila „fotografski“" snimak onog što se stvarno s čovekom zbilo.

Princip „fotografisanja“2 stvarnosti kod Dostojevskog uočio je jedan drugi umetnik, koji je naizgled veoma udaljen od realističkog metoda. Radi se o simbolisti Mihailu Vrubelju, za čija platna bismo teško mogli reći da imaju veze s fotografijom. Ipak mnoga od njih su nastala upravo po fotografijama, čije je oblike umetnik „razlagao“ na kristale, probijajući granice realnog i otkrivajući fantastično, koje bi se prema simbolističkom postulatu moglo nazvati realnošću ,realnijom od realnog“:

Usavršavanje životne tehnike - evo pravoga pulsa; on mora da postoji i u umetnosti. Nijedna ruka, nijedno oko, nikakvo strpljenje ne može biti tako objektivno, kao što je foto-aparat - na umetniku je da kroz svoju duševnu prizmu propusti sav taj živi i istiniti materijal (Федоров-Давыдов 1962: 146).

Vrubelj je upravo ovom postupku nalazio pandan u stvaralačkom metodu Dostojevskog, koji je iskazao u savetima mladom umetniku:

Mili mladiću, dođi kod mene da učiš, ti si na opasnom putu. Video sam tvoju sliku. Ona je čipkasta, a to je opasno. Ja ću te naučiti da vidiš $u$ realnom fantastično, kao na fotografiji, kao kod Dostojevskog (Федоров-Давыдов $1962,152)$.

Šta je to što u prikazivanjima činjenica života kod Dostojevskog pomera granice realnog? Navedimo kao primer priču o stradalom dečaku iz kolekcije „,sličica“ o patnjama dece Ivana Karamazova, tj. priču o osmogodišnjem dečaku, kojeg su po naredbi bogatog feudalca, na očigled njegove majke, rastrgli lovački psi. Ivan, koji ovom pričom iskušava monaštvo brataAlekseja kako bi istakao njenu dokumentarnost, odnosno verodostojnost navodi da ju je pročitao u nekom od periodičnih izdanja Arhivu ili Starini. Zapravo, kako je istražio L. P. Grosman, priča o dečaku je objavljena u Ruskom vesniku, u rubrici „Sećanja jednog kmeta“. Evo kako je ona zabeležena iz perspektive očevica:

... kod jednog vlastelina neki seoski dečak je iz svog nestašluka pogodio kamenom u nogu gazdinog hrta. Gazda je to primetio i sluge su bile prinuđene da kažu ime krivca. Sledećeg dana gazda naredi da se ide u lov. Doveli su na mesto lova i dečaka. Naređeno mu je da se svuče i trči tako nag, a za njim su pustili

\footnotetext{
${ }^{2}$ Princip „fotografisanja” stvarnosti ne treba izjednačavati s kritikom „fotografske doslovnosti”, koja se odnosi na fotografiju portreta iz vremena Dostojevskog, i koja je, po njemu, ubistvena za umetnost: „Realizam, fotografija. Fotografija koja na sebe ne liči” (Достоевский 1983: 228). Vrubelj je imao u vidu, pre svega, panoramske fotografije i moć fotoaparata da zabeleži sve pojedinosti, koje inače mogu izmaći oku prirodnog posmatrača.
} 
pse iz svih štenara, to jest da ga love. Ali hrtovi dojuriše do njega, omirisaše ga i ostaviše... Dotrčala mu je i majka, obišla je oko šume i zagrlila svoje detence. Uhvatili su je i oterali u selo i opet pustili pse! Majka je poludela i trećeg dana umrla“ - Русский вестник. 1877. № 9. 43-44. (Ветловская 2007: 492)

I evo kako je isti događaj opisan kod Dostojevskog, propušten kroz prizmu njegovog junaka - Ivana Karamazova:

Tu je štenara sa stotinu pasa, i maltene stotina psara, svi uniformisani, svi na konjima. Kad jednog dana, jedan dečko među njihovim slugama, svega od osam godinica, baci se nekako u igri kamenom, i povredi nogu omiljenog generalovog lovačkog psa. „A što moj najmili pas hramlje?“ Saopštavaju mu da se, vele, eto onaj dečko bacio kamenom na njega i nogu mu povredio. „A, ti si to!“, odmeri ga general, „drž’te ga!“ Uzeše ga, uzeše od matere, svu noć ga zadržaše u hapsu. Izjutra, tek što dan osvanu, polazi general u punoj paradi u lov. Uzjaha konja, oko njega čankolizi, psi, psari, lovci, svi na konjima. Unaokolo skupljena dvorska čeljad, zarad jače pouke, a spred sviju mati malog krivca. Izvode dečaka iz zatvora. Turoban, hladan, maglovit jesenji dan, vanredan za lov. General zapoveda da dete svuku; detence svlače do gole kože, ono drhti, obeznanilo se od straha, ne sme glasa da pusti... „Teraj ga!“, komanduje general. „Trči, trči!“” viču mu psari. Dete trči... Drži ga! ne daj!“, dere se general i napujda na njega čitav čopor hrtova... Gonio ga je kao divljač na majčine oči, dok ga psi ne rastrgoše ne komade!“ (Dostojevski 2009: 341-342).

Dostojevski je, kao što vidimo, poput slikara Vrubelja, priču kristalizovao i produbio fotografski preciznim detaljima: „stotine pasa“, „stotine psara“, „,uniforme“", „konji“", „čankolizi“, „haps“, „turoban, hladan, maglovit, jesenji dan“" i tako dalje. Pored ovoga on je uneo i izmene u siže priče, koje, međutim, nisu umanjile njenu verodostojnost, već su joj pridodale istinitost višeg reda. Po kmetovom kazivanju psi nisu odmah rastrgli dečaka, ali pošto je spahija naredio da se slučaj ponovi, može se pretpostaviti da je egzekucija izvedena do kraja. Za Dostojevskog nema sumnje da je dečak stradao, jer, čak i da je preživeo zahvaljujući „milosti“ pasa, neoboriva je istina surovo spahijino iživljavanje. Takođe, majka koja je u kmetovoj priči bila odstranjena s mesta događaja, kod Dostojevskog je sve vreme nemi posmatrač stradanja svoga sina, kao na ikonama Raspeća. Tatjana Kasatkina, autorka radova o ikoničnom čitanju Dostojevskog, govori da njegovo delo teži „ontološkoj realnosti“", i da je za Dostojevskog karakteristično ,stalno prisustvo metaistorije u istoriji, stalno pojavljivanje, prikazivanje jevanđelskih pralikova u istorijskim likovima ljudske svakodnevice, spuštanje večnosti u vreme“ (Касаткина 2004: 308).

Shodno ovome i Aleksijevič traga za istorijskim činjenicima kroz koje će se „prelomiti vreme“ i ,uloviti duh“:

...književnost se guši u svojim okvirima... Kopiranjem i činjenicama se može izraziti samo ono što se vidi okom, a kome je potreban detaljan izveštaj o zbivanjima? Potrebno je nešto drugo... Da se uhvati trenutak, istrgnut iz života $<\ldots>$ Kako je moguće istovremeno proživljavati istoriju i pisati o njoj? Ne može se svaki komad života, svakakva egzistencijalna ,prljavština“ zgrabiti za kragnu i ubaciti u knjigu. U istoriju. Treba ,prelomiti vreme“ i ,uloviti duh“ (Алексиевич 2015). 
Jedan od junaka knjige Černobiljska molitva izgovara misao koju Svetlana Aleksijevič beleži i njome naslovljava monolog svog sagovornika, tj. fotografa Viktora Latuna. On kaže, da se život ne može shvatiti ako mu se nešto ne doda. Na šta tačno misli kada ovo kaže očevidac černobiljske katastrofe? Mi bismo rekli da misli na „,iskustvene činjenice“, koje su višak u običnom životu, kao što je višak natprirodno, fantastično iskustvo. Latun je ispričao kako je fotograf postao u Černobilju i da je fotografisao očima duše: „Nisam mogao da se oslobodim novih osećanja koja sam proživeo, to je bila čitava priča moje duše. Promenio sam se... Ugledao sam svet drugim očima" (Aleksijevič 2016: 135). Dok je to govorio ređao je svoje fotografije: dečja kolica u dvorištu kuće, prozori zatvoreni zakucanim daskama i sl. Drugi sagovornik, snimatelj Sergej Gurin, ispričao je, kako je Černobilj promenio njegov način snimateljskog rada, zadat normativnim standardima zvanične, mejnstrim, dokumentaristike:

Posle snimanja vodi me veterinarski tehničar do džinovskog rova, tamo zakopavaju krave, buldožerima. Nije mi palo na pamet da snimim. Okrenuo sam leđa rovu i snimio epizodu u najboljoj tradiciji domaće filmske dokumentaristike: na buldožerima radnici čitaju novine, Pravdu, naslov ogromnim slovima: „Domovina vas neće napustiti u nesreći“. Čak sam imao i sreće: gledam - roda sleće na polje. Simbol! Ma kakva da nas je snašla nesreća - pobedićemo! Život teče dalje (Aleksijevič 2016: 136-137).

Snimatelj Gurin je osetio krivicu što je okrenuo leđa istini, odnosno razrovanoj zemlji u koju su buldožerima zakopavane krave, a snimio konstruisanu, optimističnu sliku stvarnosti. Kod Dostojevskog se govori o grehu „negledanja“, zatvaranju očiju pred činjenicama koje su suviše užasne za gledanje. U Zlim dusima Stepan Trofimovič ironiše na račun Turgenjeva (u liku pisca S. J. Karmazinova), koji je zažmurio pred užasnim prizorom ,davljenice s mrtvim detetom na mrtvim rukama“ jer nije mogao tako nešto da podnese (Достоевский 1974: 70). Kako piše Kasatkina, Dostojevski, uvodeći priču o stradalom dečaku u tekst Ivana Karamazova, primorava svoje likove, kao i samog čitaoca, da gledaju i da ne okreću glavu, pošto samo tako mogu otkriti istinski smisao onoga što se stvarno desilo, jer ,istina nije skrivena ni od koga, nije skrivena čak ni od onih koji se protiv nje bune“ (Касаткина 2004: 423). Slično prozrenje desilo se i černobiljskom snimatelju, koji se nije slučajno setio Dostojevskog na kraju svog monologa, kao i još jednog strašnog slučaja iz njegove galerije činjenica života. „Sećate li se..., — kaže Gurin, — kod Dostojevskog... Kako je čovek šibao konja po krotkim očima. Bezumni čovek! Ne po sapima, već po krotkim očima“ (Aleksijevič 2016: 145). Ipak i Dostojevski je znao da je malo onih koji gledaju. Pesnik Vladimir Majakovski, koji je s Dostojevskim imao poseban komunikacijski kod, protiveći se ljudskoj ravnodušnosti, izgovara naizgled blasfemični stih: „Ja volim da gledam kako umiru deca“. Kod Aleksijevič ima dosta slika o stradanju dece. I tu se njeni sagovornici bore s istim pitanjima koje je postavio Dostojevski, gledati ili skrenuti pogled, priznati sopstvenu krivicu i udeo u tome što se dešava i što se desilo, osuditi ili oprostiti onima koji su za to krivi i odgovorni. U najdubljem smislu prizor koji je u Černobiljskoj molitvi opisala Zoja Bruk, inspektorka za zaštitu prirode, - možda i prevazilazi priču Dostojevskog o stradalom dečaku, premda slika uopšte ne izgleda tako jezivo. Ekipa ovlašćenih lica dolazi u kontaminirano selo. Svi u belim zaštitnim odelima, dubokim čizmama, 
rukavicama. A tamo sunce sija, rascvetalo cveće, trava, meki pesak u kojem se igraju goluždrava dečica. Inspekcija ćutke uzima uzorke kontaminiranog zemljišta i odlazi: nisu bili ovlašćeni da stupaju u kontakt s lokalnim stanovništvom. U drugoj priči, seoski bolničar Bogdankevič, neguje obolelu decu, možda baš tu istu koja su se igrala u kontaminiranom pesku prilikom posete Zoje Bruk. On samo beleži stepen njhove ozračenosti: jedno ima 570 rema, drugo - 785 i tako dalje, a na pitanje da ispriča o svom iskustvu bolničar odgovara:

Ne želim da trgujem njihovom nesrećom. Da filozofiram. Morao bih da gledam u stranu. A ja ne mogu... Svaki dan slušam o čemu pričaju... Kako se žale, kako plaču... Dobri ljudi... Hoćete li da znate istinu? Sedite pored mene i zapisujte... Ali tu knjigu niko neće hteti da čita... (Aleksijevič 2016: 146).

Pored onih što kritikukuju Svetlanu Aleksijevič zato što se „,prodala“ Zapadu, što je dobila književnu nagradu za nešto, što i nije književnost, ima i mnogo onih koji je ne kritikuju, ali ne mogu da čitaju to o čemu ona piše, baš kao što je prorekao seoski bolničr Bogdankevič. Ipak, čitali to ili ne, bunili se protiv toga ili ne, kako kaže Kasatkina vezano za priču o dečaku kod Dostojevskog, istina će uvek biti tu, svima dostupna. U skladu sa ovim Konstantin Baršt ispravno tvrdi da osnovu umetničkog metoda Dostojevskog predstavlja „etički savršen (a to znači „,fantastični“) pogled na stvarnost, kojim se rasvetljava tačno, dokumentarističko predstavljanje svakodnevne realnosti, viđene ili percepirane iz najrazličitijih izvora" (Baršt 1917:169).

No, vratimo se na kraju onome zbog čega smo i započeli ovo izlaganje, tj. elementu fantastičnog u realizmu Dostojevskog i, rekli bismo, hiper-realizmu Svetlane Aleksijevič. Rekli smo, takođe, da se fikcionalno razvija na račun viška doslovnosti, viška „iskustvenih činjenica“, na čemu, koristeći arhivsko-sudske i novinske fakte, insistira Dostojevski. Upravo su ti viškovi, nagomilavanje podrobnosti ono što Dostojevski u realizmu smatra fantastičnim, a što fantastiku čini realističnom. U tom smislu, Dostojevski piše da se pisac fantastične proze Edgar Alan Po, ne može u direktnom, već samo formalno spoljašnjem smislu nazvati fantastičnim i da je savršeno odan stvarnosti: „On skoro uvek uzima isključivu stvarnost, postavlja svog junaka u krajnju spoljašnju i psihološku poziciju i s poražavajućom tačnošću priča o stanju duše tog čoveka“. Prema Dostojevskom, Po se u književnosti ističe po moći imaginacije, ali ono što ga čini apsolutno različitim od svih drugih pisaca je „moć podrobnosti“. U njegovim pripovetkama se „do tog stepena jasno vide sve podrobnosti predstavljanog lika ili događaja da nas na kraju uverava u mogućnost stvarnosti događaja, koji ili je nemoguć ili se uopšte nije ni desio“. Po je, na primer, dao neobično verodostojan opis preletanja balona preko okena iz Evrope u Ameriku, „tako podrobno, tako tačno ispunjen neočekivanim, slučajnim činjenicama da je dobio stvaran oblik, u koji su svi poverovali““ (Достоевский 1979: 88).

Za Svetlanu Aleksijevič prikupljanje iskustvenih činjenica od neposrednih učesnika događaja je deo stvaralačkog metoda. U oba slučaja „višak“ „činjenica“ nadilazi okvire običnog, normalnog i normativnog, života otvarajući vrata fantastičnom - nenormalnom i nenormativnom. Činjenice su tako neobične da, kao i u slučaju natprirodnog, izazivaju nevericu u njihovu realnost kako kod učesnika događaja tako i kod njihovih posmatrača. Ovde ne mislimo samo na događaje koji su se zbili ili nisu zbili, kao što je slučaj pogibije vojnika u Avganistanskom ratu, ili slučaj nekog „poremećenog“ studenta koji je ubio staru zelenašicu - u tome nema 
ničeg fantastičnog. Međutim, ti događaji su fantastični u smislu nagomilavanja opažaja stvari što proširuje granice realnog. Slučaj ubistva Raskoljnikova nam je svima dobro poznat sa svim ključnim signalima koji su dosad već dobili status simbola - stepenice, brava, sekira, ušice od sekire, petlja, ključ na šnuru, minđuše, kofa, tabakera. Slično „nagomilavanje“ opažaja srećemo i u opisima očevidaca užasa rata.Navešćemo primer iz Limenih dečaka:

Jednom kad vidiš kako se spaljena koža savija u rolnu... Kao kad pukne najlon čarapa... I ščepa te... Grozno je kad ubijaju životinje... Streljali su karavan, prevozio je oružje. Ljude su streljali posebno, i magarce posebno. Oni na isti način ćute i čekaju smrt. Ranjeni magarac zavija kao kad stružeš po metalu nečim metalnim. Škripi (Aleksijevič 2017: 73);

ili još jedan primer:

Čovek uopšte ne umire onako kako je to prikazano na filmu. Ne umire čovek po Stanislavskom. Pogodi ga metak u glavu - zamahne rukom i padne. Ustvari: pogodi ga metak u glavu, mozak se razleti, a on juri za njim, može tako da trči pola kilometra i da juri mozak. Zvuči apsurdno. Ustvari, trči dok ne nastupi fiziološka smrt (Aleksijevič 2017: 112).

Koliko su prizori iz knjiga Svetlane Alekijevič bliski Dostojevskom, tj. njegovom „fantastičnom realizmu“, svedoči i izjava jednog od njenih „avganistanskih" sagovornika. On kaže kako tamo nije mogao da čita svog omiljenog Dostojevskog, već je čitao naučnu fantastiku s elementima horora, koja ima mnogo više veze s fikcijom nego s realnošću: „Tamo nisam mogao da čitam svog omiljenog Dostojevskog. Mračno je. Vukao sam Bredberija. Fantastiku. Ko želi da živi večno? Niko" (Aleksijevič 2017).

Dostojevski svakako nije pisac koji može da pruži utočište u bekstvu od realnosti, ali on, može da pruži iskustvo prelaska „duha u materiju“ (Todorov 2010: 111). Zato njegova književnost, iako ostaje u sferi realnog, ima dodirne tačke s fantastičnim, upravo tim prožimanjem telesnih i duhovnih svetova, dovođenjem u pitanje granica između duha i tvari. Premda Dostojevski nije pisac „čudesnog“, junaci njegovih romana, u specifičnim „superlativnim“ stanjima doživljavaju ,iskustvo granice“ u kojem se otkriva veza s natprirodnim (Isto: 122).

Jedno takvo, sa stanovišta racionalne logike, neopisivo iskustvo imaju i knez Miškin i Parfen Rogožin u noći ubistva Nastasije Filipovne, kada sasvim jasno čuju kako je ona „ustala" $i$ hoda u susednoj sobi:

- To je, to je, to je - diže se najednom knez strašno uzbuđen. - To, to ja znam, to sam čitao... To se zove unutrašnji izliv. Dešava se, pa ni kapi ne bude. To biva kad se pogodi pravo u srce...

- Stani... Čuješ li? - naglo ga prekide Rogožin, pa uplašeno sede na svom ležištu - čuješ li?

- Ne! - isto tako brzo i uplašeno izgovori knez zagledavši se u Rogožina.

- Ide! Čuješ li? U sali...

Obojica počeše da osluškuju.

- Čujem - pouzdano prošaputa i knez. 
- Je li ide?

- Ide.

- Da zatvorim vrata ili ne?

- Zatvori...

Zatvoriše vrata, pa opet obojica legoše. Dugo su ćutali.

(Dostojevski, 1966: 785)

Kroz slično iskustvo prolazi i majka poginulog avganistanskog vojnika, kada na groblju, kao da prelazi granicu tvari, ostvaruje susret s duhom mrtvog sina:

Prvih dana tamo sam i noćila... I nisam se plašila... Sada razumem značenje ptičjeg leta, lelujanje trave. U proleće čekam cvet da izraste iz zemlje. Posadila sam visibabe... Da što pre dobijem pozdrav od sina. One se odande probijaju k meni... od njega...

Sedim tu do večeri. Do noći. Ponekad jaučem i ne čujem sebe dok ptice ne polete. Grakću vrane. Kruže nada mnom, udaraju krilima, tek se onda prenem. Prestanem da jaučem. Sve četiri godine, svaki dan dolazim. Ili ujutru ili uveče. Kad sam dobila infarkt, bila sam jedanaest dana bez svesti, nisu mi dali da ustanem. A kad sam ustala, dođem tiho do toaleta... Znači i do sina ću stići, ako padnem, pašću na njegov grob. Pobegla sam u bolničkom mantilu...

Pre toga sanjam. Pojavljuje se Valjera...

- Mamice, nemoj sutra da dolaziš na groblje. Ne treba.

Dotrčim: tiho je, tako tiho, kao da on nije tamo. Moje srce oseća - nema ga. Vrane sede na spomeniku, na ogradi i ne beže, ne kriju se od mene kao obično. Ustanem s klupe, a vrane lete preda mnom, smiruju me. Ne daju mi da odem. Šta je to? Šta hoće time da mi kažu? Odjednom se ptice smire, popnu se na drveće. I mene nešto povuče ka grobu, i tako mi bude lako na duši, prođe me nemir. To se njegov duh vratio. „Hvala vam moje ptičice, što ste me sprečile, niste mi dale da odem. Evo, dočekala sam sinčića...“ (Aleksijevič 2017: 255).

Može se reći, zajednički imenitelj ovih dveju tema „vaskrsavanja“ i pandeterminizma jeste ukidanje granice između tvari i duha. Upravo elementi fantastične književnosti i kod Dostojevskog i kod Svetlane Aleksijevič učinili su da ta stroga razdvojenost postane neizvesna.... Kako piše Todorov, jedna od karakteristika fantastične književnosti je posmatranje predmeta, prilikom čega se gube graninice između predmeta, s njihovim oblicima i bojama, i posmatrača, odnosno razlika između objekta i subjekta, što svojim iskustvom potvrđuje i Teofil Gotje: „Nekim čudnim čudom, posle nekoliko minuta posmatranja počeh da se stapam s pažljivo gledanim predmetom i sam postadoh taj predmet [...] Nisam više osećao svoje telo; spone između tvari i duha bile su raskinute" (Todorov 2010: 111, 112).

U zaključku možemo reći, da je stvaralački metod dokumentarističke proze Svetlane Aleksijevič, zasnovan na prikupljanju iskustvenih činjenica, blizak umetničkom postupku Dostojevskog, koji su i pisac i brojni potonji kritičari i teoretičari nazvali fantastični realizam. Objasnili smo da se fantastično u realizmu 
Dostojevskog, koji inače ne prelazi granice racionalno objašnjivog, postiže pomoću „pojedinosti“", koje predstavljaju višak ili ,produžetak“ u retorici opisa posmatranog događaja, lika ili predmeta. Sličan postupak otkrivamo i u opisima neposrednog, realnog iskustva likova iz romana Svetlane Aleksijevič. Dokazali smo da se višak opažajnih pojedinosti postiže, prema teorijskom okviru Cvetana Todorova, u situacijama „superlativnih stanja“, u kojima se, kao kod Dostojevskog, po pravilu, nalaze likovi Svetlane Aleksijevič. U takvim stanjima, koje je Dostojevski nazvao „krajnosti spoljašnjih i psiholoških pozicija“, dolazi do pojačane pažnje, udubljivanja u predmet posmatranja. Reč je o etičkom principu „neokretanja glave od stvarnosti“, koji je Svetlana Aleksijevič usvojila od Dostojevskog. Takvo etičko-estesko iskustvo se može nazvati ,čudom realizma“3 i duha“, što prema Cvetanu Todorovu, predstavlja jednu od bitnih karakteristika fantastične književnosti.

\section{Citirana literatura:}

Aleksijevič, Svetlana. Limeni dečaci, prevod Enisa Uspenski. Beograd: Laguna, 2017.

Dostojevski, Fjodor M. Braća Kramazovi. Jovan Maksimović (prev.). Beograd: Book, 2009.

Dostojevski, Fjodor M. Idiot. Jovan Maksimović (prev.). Beograd: Rad, 1966.

Todorov, Cvetan. Uvod u fantastičnu književnost. Beograd: Službeni glasnik, 2010.

Todorov, Tzvetan. La notion de littérature. Paris: Éditions du Seuil, 1975.

Алексиевич, Светлана. «Найти человека в человеке», 2015 <www.psychologies.ru/ people/phrase/svetlana-aleksievich-nayti-v-cheloveka-v-cheloveka, 05.05.2021>

[Aleksievič, Svetlana. "Naiti čeloveka v čeloveke“", 2015, <www.psychologies.ru/people/ phrase/svetlana-aleksievich-nayti-v-cheloveka-v-cheloveka, 05.05.2021>]

Алексиевич, Светлана. «Только в любви человек равен человеку». Российская газета, $1915<$ https://rg.ru/2015/10/08/aleksievich-site.html, 05.05 2021>

[Aleksievich, Svetlana. "Tol'ko v l'ubvi čelovek raven čeloveku“. Rossiiskaia gazeta,1915 $<$ https://rg.ru/2015/10/08/aleksievich-site.html, 05.05 2021>]

Баршт, Константин А. «'Цинический реализм' В. Буренина как претекст 'Реализма в высшем смысле'», Вопросы литературы, ноябрь-декабрь 2017: 165-190.

[Baršt Konstantin A. “'Ciničeskii realizm' V. Burenina kak pretekst 'Realizma v vysšem smysle"“. Voprosy literatury, noiabr'-dekabr' 2017: 165-190]

Ветловская, Валентина Е. Роман Ф. М. Достоевского «Братья Карамазовы». СанктПетербург: Издательство «Пушкинский дом», 2007.

[Vetlovskaia, Valentina E. Roman F. M. Dostoevskogo "Brat'ia Karamazovy“. SanktPeterburg: Izdatel'stvo „Pushkhinskiy dom“, 2007]

Достоевский, Федор М. Бесы. [В:] Полное собрание сочинений в тридцати томах, Том10. Ленинград: Наука, 1974.

[Dostoevskii, Fedor M. Besy. [V:] Polnoe sobranie sočinenii v tridcati tomah, Tom 10.

${ }^{3}$ U tom smislu Dostojevski opisuje realistično verovanje u čudo Aljoše Karamazova: „Aljoša je bio realista više nego bilo ko drugi. O, naravno u manastiru je on potpuno verovao u čuda, ali po meni, čuda realistu nikada ne zbunjuju" (Dostojevski 2009). 
Leningrad: Nauka, 1974]

Достоевский, Федор М. Дневник писателя 1877. [В:] Полное собрание сочинений в тридцати томах, Том 25. Ленинград: Наука, 1983.

[Dostoevskii, Fedor M. Dnevnik pisatelia 1877. [V:] Polnoe sobranie cočinenii v tridcati tomah, Tom 25.

Leningrad: Nauka, 1983]

Достоевский, Федор М. «Письмо А. Н. Майкову из Флоренции. 11/23 декабря 1868 года». [В:] Полное собрание сочинений в тридцати томах. Том 28(II). Ленинград: Наука, 1974.

[Dostoevskii, Fedor M. "Pis'mo A. N. Maikovu iz Florencii, 11/23 dekabria 1868 goda". [V:] Polnoe sobranie sočinenii v tridcati tomah. Tom 28 (II). Leningrad: Nauka, 1974] Достоевский, Федор Михайлович. «Предисловие к публикации 'Три рассказа' Эдгара По» [В:] Полное собрание сочинений в тридцати томах. Том 19: Статьи и заметки, 1861. Ленинград: Наука, 1979.

[Dostoevskii, Fedor Mikhaylovich. "Predyslovie k publikacii 'Tri rasskaza' Edgara Po" [V:] Polnoe sobranie sočinenii v tridcati tomah. Tom 19: Stat'i i zametki. Leningrad: Nauka, 1979]

Касаткина, Татьяна А. О творящей природе слова. Москва: ИМЛИ РАН, 2004.

[Kasatkina, Tatyana A. O tvoriaŝei prirode slova. Moskva: IMLI RAN, 2004]

Федоров-Давыдов, Алексей А. Русская пейзажная живопись. Москва: Государственное изобразительное искусство, 1962.

[Fedorov-Davydov, Alexei A. Russkaia peizažnaia živopis'. Moskva: Gosudarstvennoe izobrazitel'noe iskusstvo, 1962]

\section{Энисса Успенски}

\section{ФАНТАСТИКА РЕАЛЬНОГО В ДОКУМЕНТАЛЬНОЙ ПРОЗЕ СВЕТЛАНЫ АЛЕКСИЕВИЧ В СРАВНЕНИИ С ХУДОЖЕСТВЕННЫМ ПРИЕМОМ ФЕДОРА ДОСТОЕВСКОГО}

\section{Резюме}

Исходя из того, что для творчества Светланы Алексиевич Достоевский имеет первостепенное значение, в статье исследуем возможные точки соприкосновения ее документальной литературы с фантастическим реализмом Достоевского. Мы пришли к выводу, что для Светланы Алексиевич, как и для Достоевского, главным является наблюдение и объяснение „реальных, случившихся фактов“. У обоих авторов обнаруживаем углубленный взгляд на предмет наблюдения, которым они, не закрывая глаз даже перед самыми страшными проявлениями действительности, сумели, (соответсвенно с теоретическими рассуждениями Цветана Тодорова), размыть границы между «материей и духом», показать возможность проникновения «субъекта в объект». Благодаря данному приему документальная проза Алексиевич, вслед за реализмом Достоевского, подступила к жанру фантастической прозы. 